\title{
FIELD EVALUATION OF FUSARIUM TUMIDUM AS A BIOHERBICIDE AGAINST GORSE AND BROOM
}

\author{
J. FRÖHLICH ${ }^{1}$, J.A. ZABKIEWICZ ${ }^{2}$, A.F. GIANOTTI ${ }^{1}$, \\ J.W. RAY ${ }^{2}$, A.L. VANNER ${ }^{2}$, Z.Q. LIU ${ }^{2}$ and S. GOUS ${ }^{2}$ \\ ${ }^{1}$ Landcare Research, Private Bag 92170, Auckland, New Zealand \\ ${ }^{2}$ Forest Protection, Forest Research, Private Bag 3020, Rotorua, New Zealand
}

\begin{abstract}
Fusarium tumidum spores formulated in water and three invert emulsions were tested under field conditions as a potential bioherbicide against gorse (Ulex europaeus) and broom (Cytisus scoparius). Inundation with $F$. tumidum spores failed to induce severe disease epidemics. The invert emulsion formulants demonstrated some phytotoxicity towards gorse and Pinus radiata. Plant species and age, spore concentration and application rate all influenced the performance of the bioherbicide formulations. It will be necessary to develop further formulations that will better enhance the activity of $F$. tumidum in the field.
\end{abstract}

Keywords: bioherbicide, gorse, broom, radiata pine, Fusarium tumidum.

\section{INTRODUCTION}

Gorse (Ulex europaeus) and broom (Cytisus scoparius) are important weeds that reduce the productivity of pastures and plantation forests in New Zealand. Bioherbicides can complement or replace chemical and mechanical methods of weed control and there is strong support for their development. Fusarium tumidum is a foliar, nonsystemic pathogen that causes lesions on leaves, spines, and stems of gorse and broom as well as tip dieback on the former (Broadhurst and Johnston 1994). It requires free water to infect plants (Morin et al. 1998), which potentially limits its efficacy as a bioherbicide. A number of formulations have been developed for foliar bioherbicides that incorporate water-retaining adjuvants (Daigle et al. 1990; Womack et al. 1996). This paper reports the results of two field trials in which $F$. tumidum was applied to gorse, broom and pine (Pinus radiata) plants formulated in three emulsions of water in oil (invert emulsions) and water-based control treatments. The phytotoxic effects of the formulations alone (without spores) were also examined.

\section{Spore production and application}

\section{METHODS}

Fusarium tumidum spores were produced on solid substrate in the laboratory (Morin et al. 1998) and incorporated into a kaolin-based (aluminium silicate) wettable powder. The viability of the spores (percentage germination after $6 \mathrm{~h}$ on water agar) was determined before use and all spore concentrations cited are of viable spores. The pathogenicity of spores in the wettable powder was tested on glasshouse-grown gorse plants before each trial. Only batches of powder that caused on average $>50 \%$ tissue death (typically $\sim 75 \%$ ) were used.

Water-based spore suspensions were applied with a C-Dax sprayer fitted with an 8002 EVS nozzle (Spraying Systems) operated at $275 \mathrm{KPa}$. The invert emulsion treatments, with or without spores, were applied with an Airteck twin fluid nozzle 3573 at $100 \mathrm{KPa}$ for the liquid and $200 \mathrm{KPa}$ for air.

\section{Field trial I}

This was conducted near Tikitere, $15 \mathrm{~km}$ east of Rotorua. Gorse plants of three growth stages were used. 'Large gorse' plants were planted in the ground in prepared 
plots, five plants per plot. They were 18 months old, $1.0-1.5 \mathrm{~m}$ tall, with signs of recently flushed, soft shoots at treatment. 'GH small gorse' plants, grown in pots in a glasshouse in Auckland, were 11 weeks old and 100-120 mm tall at treatment. Five pots, each containing four plants, were placed in trays on the ground in each field plot. 'SH small gorse' plants, grown in pots in a shade house in Rotorua, were 14 weeks old at treatment and 50-100 $\mathrm{mm}$ tall. Three pots, each containing one or two plants, were placed on the ground in each plot.

There were eight treatments (Table 1). Water (control treatment) and a standard invert emulsion formulation (Invert I, details of formulations are confidential) were applied at a rate equivalent to 1000 litres/ha, both with and without $F$. tumidum spores $\left(1 \times 10^{6}\right.$ spores per $\left.\mathrm{ml}\right)$. Plastic bags were placed over half of the treated plants to provide humid conditions analogous to dew and removed 24 h later. Each treatment was applied to three plots (replicates). A randomised block design, in which each plot was treated as a separate block, was used to assign specific treatments to particular plots. Six treatments were applied on 14 April 1998 on a dull afternoon/evening during light rain. Two treatments (Invert $1+$ spores \pm bags) were applied on 15 April in the morning. Dew period and air temperature were monitored before and after treatment.

\section{Field trial II}

The second trial was conducted at the same location as the first trial and environmental conditions were monitored as before. Treatments were applied to gorse plants at three growth stages. 'Large gorse' plants were planted in the ground in field plots, five plants per plot. These were 20 months old and $0.8-1.0 \mathrm{~m}$ tall at treatment. 'Medium gorse' and 'small gorse' plants were grown in pots (one plant per pot) in a Rotorua shade house for four months and two months respectively. Six 'medium' (250-300 mm tall) and ten 'small' (40-70 mm tall) gorse plants were placed in trays on the ground in each large gorse plot. Also in each plot were five pots of broom plants, 14 weeks old, 150-180 mm tall, grown in pots in an Auckland glasshouse, one plant per pot. After treatment the potted plants were moved to a rabbit-proof enclosure, dug into the ground and watered regularly for two months. Pine plants were grown in beds in an outdoor nursery for one year and were lifted and replanted in the ground three months prior to the trial. The pines were planted in 20 plots in a separate bed to the gorse plots, there were nine pines per plot and they were $300-450 \mathrm{~mm}$ tall at the start of the trial. A randomised block design was used to assign specific treatments to particular gorse plots. The row of 20 pine plots was divided into four blocks and treatments were assigned randomly to one plot within each block.

There were 23 treatments (Table 2) and each was applied to four plots (replicates) containing gorse and broom plants. Four treatments (water, Invert I, Invert 3 and Invert C, all with $2 \times 10^{6}$ spores per ml) plus a fifth, water-without-spores (control) treatment, were also applied at 1000 litres/ha to four plots of pine seedlings. All treatments were applied on 18 November 1998.

\section{Assessments}

Disease severity on the gorse plants in Trial I was assessed as follows: $0=$ no visible symptoms, $1=1-25 \%, 2=26-50 \%, 3=51-75 \%$ and $4=76-100 \%$ necrosis. The disease ratings of the large gorse were assessed after two weeks, one month and then once a month for 11 months. A final rating and plant mortality were recorded after 18 months. The disease ratings for the $\mathrm{GH}$ and $\mathrm{SH}$ small gorse were determined after two weeks and their mortality was assessed after one month.

Disease assessments for Trial II used a modified disease-rating system. If damage was less than $25 \%$, then the actual percentage of necrotic tissue was recorded. Necrosis of $25-50 \%$ was scored as $37 \%$, necrosis of $51-75 \%$ was scored as $62 \%$ and necrosis greater than $75 \%$ was recorded as $87 \%$. The large gorse plants were rated before treatment (due to background levels of disease), then at two weeks, and one, four and five months after treatment (MAT). The small gorse and broom plants in pots were rated after two weeks, one and two MAT. The growth of pine plants was assessed by measuring their height and root collar diameter before treatment and two weeks, one and three MAT. 


\section{Statistical analysis}

Trends in the data were investigated using analysis of variance (ANOVA). Trial I was a factorial experiment with disease ratings or dry weight as the dependent variable and formulation (water or Invert I), spore presence/absence and bag presence/ absence as the main effects. A one-way ANOVA with 'treatment' (all of the possible combinations of formulation, spore concentration and application rate tested) as the main effect was also applied to the small $\mathrm{GH}$ and $\mathrm{SH}$ gorse data from Trial I and to the data from all of the plants in Trial II. Separate ANOVAs were done for each time. Treatment means were compared using Fisher's protected least significant difference. All analyses were performed using the SAS statistical package (SAS Institute Inc. 1987).

\section{Field trial I}

\section{RESULTS}

The presence of plastic bags rarely resulted in a significant increase in disease rating or a significant decrease in dry weight for the small gorse.

Treatment with water with spores caused significantly higher levels of necrosis for both $\mathrm{GH}$ and SH small gorse, and significantly decreased dry weight in GH small gorse, compared to treatment with water alone. However, on average disease ratings were $<50 \%$, and mortality was 0 , for all plants treated with water or without spores (Table 1).

The invert emulsion applied without spores was phytotoxic. It significantly inhibited growth and killed on average $9.2 \%$ of GH and $16.6 \%$ of SH small gorse (with or without bags) after one month.

\section{TABLE 1: Formulations applied and disease assessments in field trial I.}

\begin{tabular}{|c|c|c|c|c|c|c|}
\hline \multirow{4}{*}{$\begin{array}{l}\text { Plants } \\
\text { Assessment date }\end{array}$} & \multicolumn{3}{|c|}{ GH small gorse } & \multicolumn{3}{|c|}{ SH small gorse } \\
\hline & $2 \mathrm{WAT}^{1}$ & 2WAT & $1 \mathrm{MAT}^{2}$ & 2WAT & 2WAT & 1MAT \\
\hline & Rating $^{3}$ & Dry & Mortality & Rating & Dry & Mortality \\
\hline & & weight & & & weight & \\
\hline Water & 0.4 & 0.23 & 0 & 0.2 & 0.22 & 0 \\
\hline Water + bag & 0.5 & $0.18 *$ & 0 & 0.3 & 0.29 & 0 \\
\hline Water + spores & $1.1 *$ & $0.12 *$ & 0 & $0.9 *$ & 0.14 & 0 \\
\hline Water + spore + bag & $1.7 *$ & $0.13 *$ & 0 & $1.3 *$ & 0.17 & 0 \\
\hline Invert I & $0.8 *$ & $0.13 *$ & 15 & 0.6 & $0.07 *$ & 22.2 \\
\hline Invert $1+$ bag & 0.5 & $0.13 *$ & 3.4 & 0.3 & 0.13 & 11.1 \\
\hline Invert I + spores & $2.4 *$ & $0.11 *$ & 55 & $0.8 *$ & 0.13 & 11.1 \\
\hline Invert I + spores + bag & $2.4 *$ & $0.13 *$ & 58 & $1.4 *$ & 0.11 & 0.0 \\
\hline
\end{tabular}

${ }^{1} \mathrm{WAT}=$ weeks after treatment.

${ }^{2} \mathrm{MAT}=$ months after treatment.

${ }^{3}$ Rating: $0=0 \%, 1=1-25 \%, 2=26-50 \%, 3=51-75 \%$ and $4=76-100 \%$ necrosis.

$*$ Result is significantly different from the relevant water control $(\mathrm{P}<0.05)$.

The GH small gorse was highly susceptible to the Invert I with spores treatment, with on average $50-75 \%$ necrosis, significantly reduced dry weight and $56.5 \%$ mortality. In contrast, while this treatment resulted in a significant increase in disease rating of $\mathrm{SH}$ gorse, there was no significant reduction in growth and an average mortality of only $5.5 \%$. A factorial ANOVA of the dry weight data confirmed that while both of the factors formulation and spores had a significant impact on GH gorse (the interaction between the two factors was not significant), only formulation had a significant effect on the growth of SH gorse.

The large gorse plants were monitored over 18 months. A factorial ANOVA revealed no significant interactions between bag presence/absence, spore presence/ absence and formulation (water or Invert I). Bag presence/absence was not significant 
at any of the 14 assessment dates $(\mathrm{P}>0.05)$. Treatments including $F$. tumidum spores were associated with significantly greater $(\mathrm{P}<0.05)$ levels of necrosis than treatments without spores at two weeks after treatment (WAT) and one, two, three, four and seven MAT. Plants treated with Invert I with and without spores were given significantly higher disease ratings $(\mathrm{P}<0.05)$ than those treated with water with and without spores at every assessment date except the last one at 18 MAT (Fig. 1). Assessment of large plant mortality indicated that all stems survived, despite considerable necrosis of the spines (50-75\% in the Invert 1 with spores treatment).

\section{Field trial II}

Probably as a result of the dry, sunny conditions under which this trial was conducted, levels of infection were low (usually $<25 \%$ ) for all treatment/plant combinations at all dates.

TABLE 2: The rating ${ }^{1}$ of various treatments on gorse and broom in field trial II.

\begin{tabular}{|c|c|c|c|c|}
\hline \multirow{2}{*}{$\begin{array}{l}\text { Plant Species } \\
\text { Treatment }\end{array}$} & \multicolumn{2}{|c|}{ Gorse } & \multicolumn{2}{|c|}{ Broom } \\
\hline & $\begin{array}{c}\text { Small } \\
\text { 2MAT }^{2}\end{array}$ & $\begin{array}{l}\text { Medium } \\
\text { 2MAT }\end{array}$ & $\begin{array}{l}\text { Large } \\
\text { 4MAT }\end{array}$ & $\begin{array}{l}\text { Small } \\
\text { 2MAT }\end{array}$ \\
\hline Water@1000³ & 0.7 & 0.5 & 12.4 & 0.3 \\
\hline Invert $1 @ 500$ & 1.8 & 2.5 & 12.7 & 2.1 \\
\hline Invert1 @1000 & $4.7 *$ & $12.0 *$ & 21.3 & 2.7 \\
\hline Invert $3 @ 500$ & 1.9 & $6.0^{*}$ & 11.8 & 1.0 \\
\hline Invert3@1000 & $3.2 *$ & $6.0 *$ & 11.5 & 0.8 \\
\hline Invert C@500 & 0.6 & 3.4 & 12.8 & 0.1 \\
\hline Invert C@1000 & 1.3 & $7.1 *$ & 13.7 & 0.5 \\
\hline Water+1 x $10^{6}$ spores@ 500 & $3.7 *$ & 1.6 & 14.5 & 1.1 \\
\hline Water+1 x $10^{6}$ spores @ 1000 & $4.4 *$ & 2.6 & 11.7 & $3.2 *$ \\
\hline Invert $1+1 \times 10^{6}$ spores @ 500 & 2.6 & $6.8^{*}$ & 9.2 & $5.2 *$ \\
\hline Invert $1+1 \times 10^{6}$ spores @ 1000 & 2.9 & $12.7 *$ & 16.3 & $4.1 *$ \\
\hline Invert $3+1 \times 10^{6}$ spores @ 500 & 2.4 & 4.2 & 8.0 & 0.4 \\
\hline Invert $3+1 \times 10^{6}$ spores $@ 1000$ & $3.9 *$ & $13.5^{*}$ & 22.4 & 0.9 \\
\hline Invert $\mathrm{C}+1 \times 10^{6}$ spores $@ 500$ & 1.1 & 2.6 & 13.2 & 1.0 \\
\hline Invert $C+1 \times 10^{6}$ spores @ 1000 & 2.4 & 1.9 & 11.3 & 1.7 \\
\hline Water+2 2 10 $10^{6}$ spores @ 500 & $7.2 *$ & 3.6 & 6.7 & $9.6^{*}$ \\
\hline Water+2 x $10^{6}$ spores @ 1000 & $5.4 *$ & 3.7 & 12.1 & 2.0 \\
\hline Invert $1+2 \times 10^{6}$ spores @ 500 & $4.6 *$ & $11.7 *$ & 9.0 & $7.6 *$ \\
\hline Invert $1+2 \times 10^{6}$ spores @ 1000 & $7.2 *$ & $7.7 *$ & 13.9 & $6.0 *$ \\
\hline Invert $3+2 \times 10^{6}$ spores @ 500 & 1.8 & 4.5 & 12.2 & 1.9 \\
\hline Invert $3+2 \times 10^{6}$ spores @ 1000 & $4.6 *$ & $16.6^{*}$ & 18.1 & 0.5 \\
\hline Invert C+2 x 106 spores@ 500 & 1.6 & 1.3 & 8.1 & $2.8^{*}$ \\
\hline Invert $C+2 \times 10^{6}$ spores @ 1000 & 2.4 & 3.5 & 16.6 & 2.2 \\
\hline
\end{tabular}

${ }^{1}$ Each rating is the average $\%$ necrosis from all plants receiving this treatment.

${ }^{2} \mathrm{MAT}=$ months after treatment.

${ }^{3} \mathrm{All}$ application rates are given in litres/ha.

$*$ Result is significantly different from the relevant water control $(\mathrm{P}<0.05)$.

Invert I and Invert 3 without spores resulted in significantly greater levels of dead tissue than treatment with water alone in small and medium gorse (Table 2), indicating a formulation phytotoxicity effect. Invert $\mathrm{C}$ without spores only slightly damaged medium sized gorse when applied at 1000 litres/ha.

Higher concentrations of $F$. tumidum spores generally appeared to increase disease incidence in all four formulations on small and medium gorse and broom plants. Increasing application volume also increased disease ratings. 


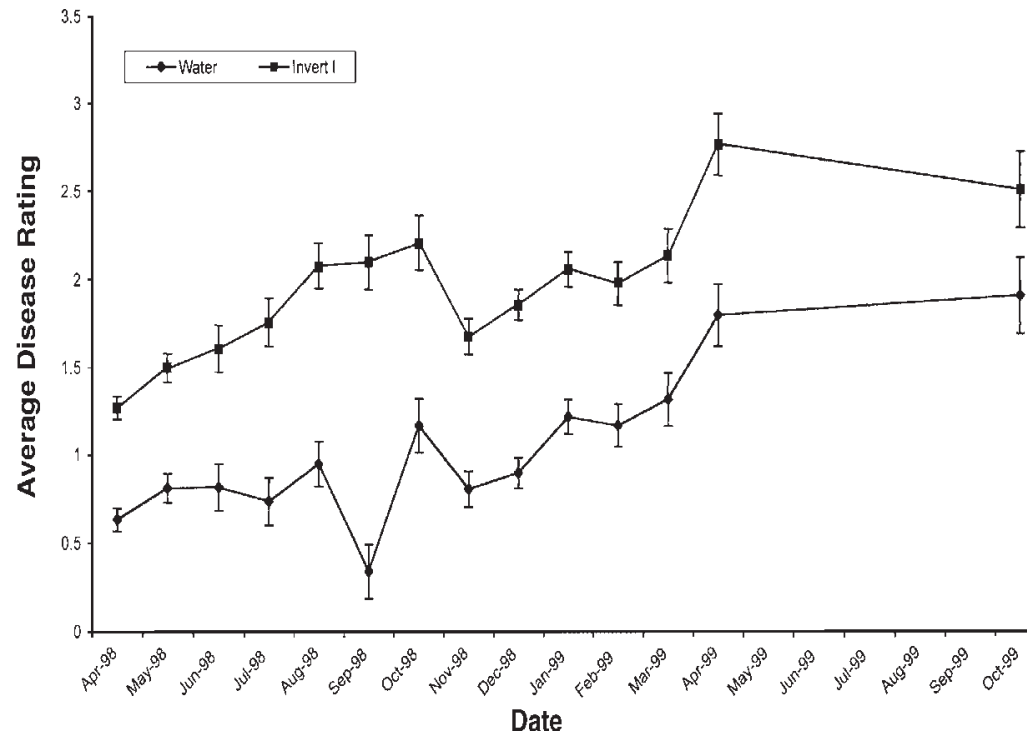

FIGURE 1: Average disease ratings (0-4 scale) of large gorse plants in field Trial I. Water and Invert I results presented are the means of data from plants treated with and without bags and with and without spores. Y-error bars show standard error.

Fusarium tumidum spores had a slightly greater degree of impact when applied with Invert 3 than with Invert C. While the fungus induced higher disease ratings on small gorse and broom when combined with Invert I, this was almost certainly a result of the higher phytotoxicity of this formulation. There were no significant differences between any of the treatments and the water control for the large gorse plants 4 MAT.

After 3 months pines treated with water with spores were not significantly different from those treated with water only, but pines treated with Invert 1 with spores, Invert 3 with spores and Invert $C$ with spores had significantly lower bulk index values than those treated with water with spores. The growth of pine seedlings was most inhibited by treatment with Invert I with spores compared with water treatments (Fig. 2). There was no sign of phytotoxicity from the formulations on the pines during the first month but growth retardation occurred slowly thereafter (Fig. 2).

\section{DISCUSSION}

While levels of disease were on the whole considerably greater in Trial I than in Trial II, the results of the two trials are generally consistent. While the application of $F$. tumidum spores in water sometimes resulted in significant necrosis, tissue death greater than $50 \%$ and plant mortality were only seen in treatments in which spores were combined with an invert formulation.

The plastic bags used to provide humid conditions analogous to $24 \mathrm{~h}$ of dew resulted in very few significant increases in the disease ratings of the plants in Trial I. Humidity was not measured within the bags so it is not known whether the bags failed to provide humid conditions as intended.

The Invert I formulation was associated with significant plant damage to gorse, broom and pine and thus has less commercial potential than the others tested. There was an initial effect from the fungus (additional to the formulation toxicity) on the large gorse in Trial I but it did not persist beyond four MAT, apart from a brief resurgence at seven MAT. The damage caused by the other formulation constituents lasted for the duration of the trial (Fig. 1). 


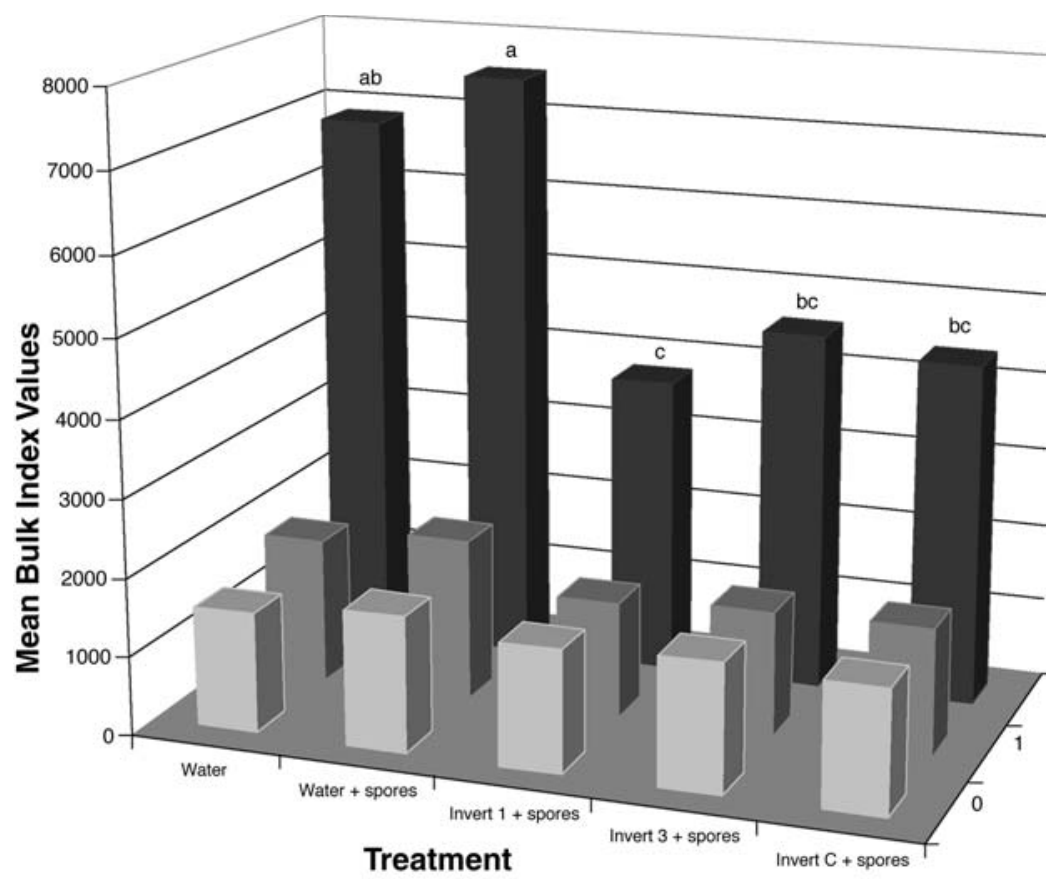

FIGURE 2: Mean Bulk Index values of pine plants at 0,1 and 3 months after treatment (MAT). Columns with a common letter do not differ significantly $(\mathbf{P}=\mathbf{0 . 0 5})$.

There was a gradual increase in disease rating on the large gorse in Trial I for all eight treatments (Fig. 1). Reasons for this may include the natural senescence of the lower parts of the gorse plants as they aged and/or higher than normal levels of $F$. tumidum spores in the area as a result of fruiting bodies developing on the dead gorse tissues in the more successful treatments. The significantly higher disease levels of plants treated with spores seven MAT could also have resulted from a brief epidemic brought about by re-infection as the weather warmed in late spring. The cause of the dip in disease ratings of plants treated with water with and without spores in September 1998 is unknown.

The effect of treatments varied considerably with plant species and age. In Trial I shade-house-grown (SH) small gorse plants appeared to be more resistant to $F$. tumidum than glasshouse-grown $(\mathrm{GH})$ plants especially in terms of their dry weight (Table 1). Both small and medium SH gorse was again quite resistant to damage in Trial II. The highest average disease rating for these plants was $13.2 \%$ and $18 \%$ respectively at one MAT.

The large gorse in Trial II had higher disease ratings (up to 22.4\%, four MAT) but these plants had high disease levels before the trial started (up to $8.1 \%$ ) and there were no significant differences at four MAT between plants treated with spores and those receiving only water (Table 2 ).

The small broom plants seemed more resistant to phytotoxic effects of the invert emulsions alone than the gorse (Table 2). However, this was probably an artefact of the scoring method as the broom plants shed their damaged leaves and only attachedtissues were scored for necrosis. 
Results suggest that an application rate of $1 \times 10^{6}$ spores at 500 litres/ha would be inadequate, $2 \times 10^{6}$ spores at 1000 litres/ha would be wasteful, and either $2 \times 10^{6}$ spores at 500 litres/ha or $1 \times 10^{6}$ spores at 1000 litres/ha would be equally effective.

Although the invert emulsion formulations under investigation have been shown to successfully retain moisture around $F$. tumidum spores in the laboratory, they have failed to induce severe disease epidemics in the field. This clearly indicates that it will be necessary to develop further formulations that will better enhance the activity of $F$. tumidum in the field.

\section{ACKNOWLEDGEMENTS}

We wish to thank L. Lester and C. Winks for their assistance with plant propagation and K.D. Steele and G. Coker for assistance with field trials. P. Johnston, G. Bourdôt and A. Rahman commented on the manuscript. This work was funded by the New Zealand Foundation for Research, Science and Technology.

\section{REFERENCES}

Broadhurst, P.G. and Johnston, P.R., 1994. Gibberella tumida sp. nov. - teleomorph of Fusarium tumidum from gorse in New Zealand. Mycol. Research 98: 729-732.

Daigle, D.J., Connick, W.J., Jr, Quimby, P.C., Jr, Evans, J., Trask-Morrell, B. and Fulgham, F.E., 1990. Invert emulsions: carrier and water source for the mycoherbicide, Alternaria cassiae. Weed Technol. 4: 327-331.

Morin, L., Gianotti, A.F., Barker, R. and Johnston, P.R., 1998. Favourable conditions for the bioherbicide candidate Fusarium tumidum to infect and cause severe disease on gorse (Ulex europaeus) in a controlled environment. Biocontrol Sci. Technol. 8: 301-311.

SAS Institute, Inc., 1987. SAS/STAT T' ${ }^{\mathrm{M}}$ Guide for Personal Computers; SAS institute, Inc., Cary, NC., USA.

Womack, J.G., Eccleston, G.M. and Burge, M.N., 1996. A vegetable oil-based invert emulsion for mycoherbicide delivery. Biol. Control 5: 255-264. 